\title{
Effects of Preference for Semi-permanent Makeup on Procedure Satisfaction
}

\author{
Soo-Nam Hong \\ Department of Beauty Business, Bucheon University, Bucheon-si, Gyeonggi-do, Korea
}

Corresponding author: Soo-Nam Hong, Department of Beauty Business, Bucheon University, 25 Sinheung-ro, 56 beon-gil, Bucheon-si, Gyeonggi-do 14632, Korea

Tel.: +82 326100781

Fax: +82 326100789

Email:sn1228@naver.com

Received July 11, 2017

Revised November 12, 2017

Accepted November 30, 2017

Published June 30, 2018

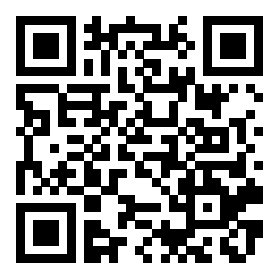

\begin{abstract}
Purpose: This study aimed to verify the effects of preference for semi-permanent makeup, a recent practical technique in the beauty industry, on procedure satisfaction. Methods: The study included 262 women in their 20 s and 50s living in Seoul and Gyeonggi province. The data collection period was from February 20, 2017 to April 5, 2017. Data analysis methods included frequency analysis, reliability analysis, independent samples $t$-test and one-way analysis of variance (ANOVA). Duncan test was performed for post-analysis; correlation and linear regression analysis were also performed. Results: The effects of preference for semi-permanent makeup on the satisfaction with procedure description were found to be statistically significant, i.e., the higher the technique and trend preference per independent variable, the higher the satisfaction with procedure description. The effects of this preference on technique satisfaction were also found to be statistically significant, i.e., the higher the technique and trend preference per independent variable, the higher technique satisfaction. Lastly, the effects of this preference on the satisfaction with procedure environment, were also found to be statistically significant, i.e., the higher the technique and trend preference per independent variable, the higher the satisfaction with procedure environment. Conclusion: Therefore, preference for semi-permanent makeup was found to be an important factor for the satisfaction with procedure environment. Thus, because semi-permanent makeup is a field that is sensitive to esthetic sense and beauty trends, customer satisfaction with semi-permanent makeup will increase if methods of procedure explanation, technique, and procedure environment are improved.
\end{abstract}

Keywords: Semi-permanent makeup, Permanent makeup, Makeup, Preference, Procedure satisfaction

\section{Introduction}

최근 뷰티 분야에 편리함과 미적인 부분을 동시에 충족시킬 수 있는 반영구화장에 대한 관심이 높아지고 있다. 이는 메이크업의 일환으로 개인의 외적 이미지에 중요한 영향을 미치며, 인상 형 성 및 신체적 매력 연출을 위한 중요한 표현수단이다(Choi 2017; Cho \& Yang, 2017). 국내 반영구 시장은 창업과 취업은 물론이 고 활성화를 위한 다양한 최신기법, 특화된 테크닉을 개발하고 있 으며, 교육분야에서는 실습과 이론이 수록된 체계적이고 전문성 있는 교재개발이 이루어지고 있다. 이러한 현상은 국내시장은 물 론이고 점진적으로 확대되고 있는 해외시장의 수요를 감안한다면
보다 차별화되고 전문적인 콘텐츠 개발의 필요성을 의미한다.

반영구화장에 대해서 Hill (2006)은 매일 하는 외모관리의 수 단으로 피부에 반영구적인 색소를 주입하는 방법이며, 메이크 업 시간을 단축시켜 줌과 동시에 단점을 커버하는 특성과 화장품 사용을 제한할 수 있는 새로운 미용방법이라고 하였다(Baek \& Park, 2017) 또한 반영구화장은 자신의 신체에 예술적인 표현과 미적인 관점에서 미용을 위한 목적으로 사용되고 있으며(DeterWolf et al., 2016), 아름다움을 추구하는 것과 콤플렉스 해 소, 편의성 등의 다양한 원인에서 시작한다(Shelton \& Peters, 2006). 반영구화장에 대한 개념은 얼굴의 윤곽을 수정한다는 의 미로 컨투어 메이크업(contour makeup), 오랜 시간을 유지한 
다고 하여 롱 타임 메이크업(long time makeup), 얼굴에 예술 적인 감각을 표현한다는 뜻으로 아트 메이크업(art makeup) 등 으로 사용되고 있으며, 의학계에서는 미세 색소침착술(micro pigmentation)이라고도 한다(Cho \& Lee, 2013). 반영구는 문 신처럼 영구적이지 않아 시간이 경과되면서 지워지거나 흐려지 는 경향이 많고, 이를 제거하기 위해서는 레이저를 활용하여 피 부의 색소를 없애야 한다(Chung et al., 2016). 반영구화장의 표현기법은 다양한 테크닉 개발로 인해 엠보, 수지, 자연눈썹, 화장눈썹, $3 \mathrm{D}, 4 \mathrm{D}$ 등 그 명칭과 기법이 혼용되어 쓰여지고 있으 며, 기기사용 유무 및 종류에 따라 머신기법과 수지기법으로 분 류한다(Cho \& Lee, 2013). 최근 관련된 교육분야에서는 다양한 반영구화장 기법은 물론이고 제품 및 염료 개발, 고객 서비스, 마케팅 노하우, 서비스 정신 등 단순히 기술적인 테크닉만 교육 하는 것이 아닌 아이템과 콘텐츠까지 수출하고 있어, 이에 대한 수요는 점진적으로 확대될 것으로 전망한다.

반영구화장에 대해서 진행된 선행 연구결과를 살펴보면, 실 제 경험자는 이를 전문적으로 시술하는 전문가보다 메이크업과 이미지 메이킹을 배운 전문가의 시술이 테크닉적인 부분과 시술 설명 등에 있어서 효과적이라고 하였고, 시술장소로는 반영구화 장 전문숍을 선호한다고 하였다(Park, 2016; Seo, 2013). 또 한 반영구화장의 시술기법에 대해서는 시술경험 한국인의 경우 $54.7 \%$ 가 기법 자체를 잘 모른다고 응답하였고, 일본인은 그라 데이션, 미국인은 페더링 기법의 선호도가 가장 높았으며, 컬러 는 한국인과 일본인은 갈색, 미국인은 검정색을 가장 선호한다고 하였다(Kim \& Choi, 2014). 시술만족도는 상품이나 서비스를 선택하고 비교 및 평가하는 것으로 구매 후 성과에 대해 소비자 가 느끼는 감정의 만족도이며, 이에 대한 구분은 소비경험과 서 비스를 통한 경험결과와 평가과정에 초점을 맞추고 사용 전 기대 와 사용 후 소감이 높은 것을 의미한다(Bloemer \& De Ruyter, 1998). Anderson et al. (1994)은 누적되는 만족은 장기적인 소 비경험을 통해 고객이 얻게 되는 전반적 경험에 대한 평가로 제 시되고, 이는 모든 분야에 마찬가지로 적용이 되며, 고객이 제품 구매 및 경험에 참여하여 만족하게 되면 재이용 의도가 높아지 고, 고객만족도는 고객충성도를 높이고 긍정적인 구전효과와 관 련이 깊다고 하였다.

반영구화장의 시술만족도의 요인은 연구자마다 달리 정의하 고 있는데 대부분 시술환경, 시술효과 및 관리, 시술 시 고려요 인 등으로 정의하였고(Park, 2016), Hong (2017)에서는 고객 의 피부타입, 얼굴형, 이미지, 선호도, 사전 디자인 작업 등을 고 려하여 고객과의 충분한 상담이 이루어진 후 진행하는 것이 좋다 고 하였다. 앞서 진행되었던 선행연구에서는 반영구화장에 대해 서 단순한 선호도와 시술만족도만을 조사하였으나 본 연구에서 는 반영구화장에 대한 선호도와 그에 따른 시술만족도를 조사하 여 선행연구와의 차별성을 제시한다. 본 연구의 이해를 돕기 위
해 반영구화장의 시술설명, 테크닉, 시술환경을 포함하여 시술만 족도라고 통칭하며, 이에 대한 만족도에 따라 추가구매 및 구전 의도 등으로 이어질 수 있어 이를 중심으로 연구하였다.

따라서 본 연구의 목적은 반영구화장 선호도가 시술만족도에 미치는 영향에 대해서 알아보고자 하며, 이를 통해 반영구 분야 의 전문가는 고객의 니즈를 반영한 시술테크닉을 개발하고 반영 구화장이 뷰티 분야의 고부가가치를 창출하는 콘텐츠 및 실용 메 이크업 활용도움 자료로 사용되고자 한다.

\section{Methods}

\section{1. 연구모형 및 가설}

본 연구는 반영구화장 선호도가 시술만족도에 미치는 영향을 파악하고자 하였다. 이에 따라 반영구화장 선호도를 테크닉 선 호, 트렌드 선호로 설정하고, 시술만족도인 시술설명, 테크닉, 시술환경에 미치는 영향을 분석하고자 연구모형 및 가설을 설정 하였다(Figure 1).

H1. 반영구화장 선호도가 시술설명 만족도에 정(+)의 영향을 미칠 것이다.

H1-1. 테크닉 선호가 시술설명 만족도에 정(+)의 영향을 미 칠 것이다.

H1-2. 트렌드 선호가 시술설명 만족도에 정 $(+)$ 의 영향을 미 칠 것이다.

H2. 반영구화장 선호도가 테크닉 만족도에 정(+)의 영향을 미 칠 것이다.

H2-1. 테크닉 선호가 테크닉 만족도에 정 $(+)$ 의 영향을 미칠 것이다.

$\mathrm{H} 2-2$. 트렌드 선호가 테크닉 만족도에 정(+)의 영향을 미칠 것이다.

H3. 반영구화장 선호도가 시술환경 만족도에 정(+)의 영향을 미칠 것이다.

H3-1. 테크닉 선호가 시술환경 만족도에 정 $(+)$ 의 영향을 미 칠 것이다.

H3-2. 트렌드 선호가 시술환경 만족도에 정 $(+)$ 의 영향을 미 칠 것이다.

\section{2. 측정도구의 구성}

일반적 특성 6 문항, 선호도 6 문항은 Kim \& Choi (2014), Seo \& Lee (2013)의 문항을, 시술만족도 10문항은 Park (2016), Hong (2017)의 설문문항을 참고하여 본 연구에 맞게 수정 - 보완하였다. 


\section{3. 조사대상 및 방법}

조사대상자는 서울, 경기도에 거주하는 20-50대 여성 280명 으로, 타 연령대에 비해 외모와 자기관리 및 사회적인 활동이 많 은 20-40대와 최근 삶의 질이 높아짐에 따라 외모에 대한 투자 와 자기관리 성향이 높아진 50 대까지로 선정하였다.

설문과정에서 불성실한 설문지 18 부를 제외한 262 부를 통 계분석에 활용하였고, 자료수집 기간은 2017년 2월 20일부터 2017년 4월 5일까지이다.

\section{4. 자료분석 방법}

수집된 자료의 통계처리는 데이터 코딩(coding)과 데이터 클리 닝(cleaning) 과정을 거쳐, Statistical Package for the Social Sciences (SPSS) v. 21.0 통계 패키지 프로그램(IBM, USA)을 활용하여 분석하였다. 첫째, 조사대상자의 일반적 특성을 알아보 기 위하여 빈도분석을 실시하였다. 둘째, 측정도구의 타당성 검 증을 위해 탐색적 요인분석을 실시하였으며, 신뢰도 검증을 위 해 Cronbach's $\alpha$ 계수를 산출하였다. 셋째, 반영구화장 선호도 와 시술만족도를 알아보고, 조사대상자의 일반적 특성에 따라 차 이가 있는지를 알아보기 위하여 독립표본 $t$-test 및 일원변량 분석 one-way ANOVA를 실시하였으며, 사후검증 방법으로는 Duncan test를 실시하였다. 넷째, 각 변수 간에 상관관계를 알 아보기 위하여 상관관계분석을 사용하였으며, 가설검증을 위하 여 선형회귀분석을 실시하였다.

\section{Results and Discussion}

\section{1. 조사대상자의 일반적 특성}

조사대상자의 일반적 특성을 알아보기 위하여 빈도분석을 실시한 결과는 Table 1 과 같다. 분석결과 성별은 여자 232 명 $(88.5 \%)$, 남자 30 명 $(11.5 \%)$ 으로 나타났고, 연령은 20 대 59 명 $(22.5 \%), 30$ 대 62명 $(23.7 \%), 40$ 대 93명 $(35.5 \%), 50$ 대 48 명 $(18.3 \%)$ 으로 나타났다. 결혼여부는 미혼 73 명 $(27.9 \%)$, 기 혼 189 명 $(72.1 \%)$ 으로 나타났고, 최종학력은 고등학교 졸업 이 하 148명(56.5\%), 2년제 졸업 39명(14.9\%), 4년제 졸업 63 명 $(24.0 \%)$, 대학원 졸업 12 명 $(4.6 \%)$ 으로 나타났다. 직업은 주 부 63명(24.0\%), 학생 46명(17.6\%), 교육직 38명(14.5\%), 전 문직 37명 $(14.1 \%)$, 자영업 23 명 $(8.8 \%)$, 서비스업 21 명 $(8.0 \%)$ 순으로 나타났고, 월평균 소득은 100 만원 미만 103명(39.3\%), 100-200만원 미만 67명(25.6\%), 200-300만원 미만 45명 (17.2\%), 300만원 이상 47 명(17.9\%)으로 나타났다.

\section{2. 측정도구의 타당성 및 신뢰도 검증}

변수의 타당성을 검증하기 위해 본 연구에서는 구성개념 타
당도를 검증하기 위한 탐색적 요인분석(exploratory factor analysis)을 사용하였다. 특히, 요인의 수를 최소화하여 정보 의 손실을 최소화하기 위해 주성분 분석(principal component analysis) 방식을 이용하였고, 회전방식은 직각회전인 베리맥스 (varimax) 방식을 사용하여 고유 값이 1.0 이상인 요인에 한하 여 요인적재량이 0.4 이상인 항목들을 유의한 것으로 설정하여 요인 수를 2 개로 결정하였다.

요인분석은 분석방법의 특성상 각 항목들 간의 상관관계가 높 아야 하는데 Kaiser-Meyer-Olkin (KMO) 측도와 Bartlett의 구형성 검정은 각 항목들 간의 상관행렬을 확인함으로써 사용 항 목들이 요인분석에 적합한지를 구분하는 방법이다. $\mathrm{KMO}$ 는 변 수 쌍들 간의 상관관계가 다른 변수에 의해 잘 설명되는 정보를 나타내는 것이므로 이 측도의 값이 작으면 요인분석을 위한 변수 선정이 좋지 않음을 나타낸다. 보통 $\mathrm{KMO}$ 값이 0.90 이상이면 아주 좋은 것이고 0.50 이하이면 변수로서 받아들일 수 없는 것 으로 본다. 또한 본 연구에서 다 문항 척도로 측정된 문항이 동질 적인 문항들로 구성되었는지 신뢰도를 검증하기 위해 문항간의 내적 일치도를 보는 Cronbach's $\alpha$ 계수를 산출하였다. 일반적 으로 신뢰도의 척도인 Cronbach's $\alpha$ 값은 정해진 기준이 없지만 0.60 이상이면 신뢰도가 있다고 보며 0.50 이상이면 분석하는데 큰 문제가 없는 것으로 본다.

1) 반영구화장 선호도에 대한 타당성 및 신뢰도 검증

반영구화장 선호도에 대한 타당성 및 신뢰도 검증 결과는 Table 2 와 같다. 먼저 Bartlett의 단위행렬 점검 결과 $\chi^{2}=601.537$ $(p=0.000)$ 이므로 변수들 사이에 요인을 이룰만한 상관관계가 충 분하고, $\mathrm{KMO}$ 의 표본적합도 점검결과 $\mathrm{KMO}$ 값이 0.670 으로 나 타났으며, 공통성 등을 점검한 결과에서도 측정 자료의 요인분석 가정을 만족시키므로 다음과 같이 요인분석을 실시하였다. 그 결 과 총 2 개의 요인이 도출되었고 각 요인을 구성하는 문항들의 중 심개념을 바탕으로 요인 명을 부여하였다. 요인 1 (36.896\%)은 '테크닉 선호'로 명명하였고, 요인 2 (36.493\%)는 '트렌드 선호' 로 명명하였다. 이 2 개의 요인 적재 값이 \pm 0.4 이상으로 나타나 추출된 요인은 타당성이 확보된 것으로 분석되었으며, 신뢰도 또 한 0.60 이상으로 나타나 신뢰할만한 수준인 것으로 볼 수 있다.

2) 반영구화장 시술만족도에 대한 타당성 및 신뢰도 검증

반영구화장 시술만족도에 대한 타당성 및 신뢰도 검증 결과는 Table 3 과 같다. 먼저 Bartlett의 단위행렬 점검 결과 $\chi^{2}=1794.149$ $(p=0.000)$ 이므로 변수들 사이에 요인을 이룰만한 상관관계가 충분 하고, $\mathrm{KMO}$ 의 표본적합도 점검결과 $\mathrm{KMO}$ 값이 0.867 로 나타났으 며, 공통성 등을 점검한 결과에서도 측정 자료의 요인분석 가정을 만족시키므로 다음과 같이 요인분석을 실시하였다. 그 결과 총 3 개 의 요인이 도출되었고 각 요인을 구성하는 문항들의 중심개념을 바 
Table 1. General characteristics

\begin{tabular}{|c|c|c|c|}
\hline Item & & Frequency $(\mathrm{N})$ & Percentage (\%) \\
\hline \multirow{2}{*}{ Gender } & Female & 232 & 88.5 \\
\hline & Male & 30 & 11.5 \\
\hline \multirow{4}{*}{ Age } & $20-29$ years old & 59 & 22.5 \\
\hline & $30-39$ years old & 62 & 23.7 \\
\hline & 40-49 years old & 93 & 35.5 \\
\hline & 50-59 years old & 48 & 18.3 \\
\hline \multirow{2}{*}{ Marital status } & Single & 73 & 27.9 \\
\hline & Married & 189 & 72.1 \\
\hline \multirow{4}{*}{ Final education } & High school graduate or below & 148 & 56.5 \\
\hline & College graduate & 39 & 14.9 \\
\hline & University graduate & 63 & 24.0 \\
\hline & Graduate school & 12 & 4.6 \\
\hline \multirow{7}{*}{ Job } & Student & 46 & 17.3 \\
\hline & Self-employment & 23 & 8.8 \\
\hline & Service business & 21 & 8.0 \\
\hline & Profession & 37 & 14.1 \\
\hline & Education & 38 & 14.5 \\
\hline & Housewife & 63 & 24.0 \\
\hline & Others & 34 & 13.0 \\
\hline \multirow{4}{*}{ Monthly average income } & $<1$ million won & 103 & 39.3 \\
\hline & 1-2 million won & 67 & 25.6 \\
\hline & 2-3 million won & 45 & 17.2 \\
\hline & $\geq 3$ million won & 47 & 17.9 \\
\hline Total & & 262 & 100.0 \\
\hline
\end{tabular}

Table 2. Validation of the validity and reliability of semi-permanent makeup preferences

\begin{tabular}{|c|c|c|}
\hline \multirow[b]{2}{*}{ Item } & \multicolumn{2}{|c|}{ Factors } \\
\hline & $\begin{array}{l}\text { Technique } \\
\text { preference }\end{array}$ & $\begin{array}{c}\text { Trend } \\
\text { preference }\end{array}$ \\
\hline I prefer a natural semi-permanent eyebrow makeup & 0.801 & 0.036 \\
\hline I prefer my own eyebrow design & 0.888 & -0.080 \\
\hline I prefer a more natural semi-permanent shape than a clear semi-permanent shape & 0.847 & 0.052 \\
\hline I prefer semi-permanent eyebrow makeup with a trendy design & 0.220 & 0.768 \\
\hline I prefer an eyebrow shape that is more popular than my eyebrow shape & -0.100 & 0.883 \\
\hline I prefer an eyebrow color that is more popular than my eyebrow color & -0.093 & 0.900 \\
\hline Eigen value & 2.214 & 2.190 \\
\hline Distributed description (\%) & 36.896 & 36.493 \\
\hline Cumulative distributed description (\%) & 36.896 & 73.389 \\
\hline Reliability & 0.804 & 0.812 \\
\hline $\mathrm{KMO}=0.670 ;$ Bartlett's test $x^{2}=601.537(\mathrm{df}=15, p=0.000)$ & & \\
\hline
\end{tabular}

KMO, Kaiser-Meyer-Olkin; df, degree of freedom. 
Table 3. Verification of validity and reliability of semi-permanent makeup procedure satisfaction

\begin{tabular}{|c|c|c|c|}
\hline \multirow[b]{2}{*}{ Item } & \multicolumn{3}{|c|}{ Factors } \\
\hline & Technique & $\begin{array}{l}\text { Procedure } \\
\text { environment }\end{array}$ & $\begin{array}{l}\text { Procedure } \\
\text { description }\end{array}$ \\
\hline I am satisfied with the semi-permanent makeup design & 0.893 & 0.131 & 0.213 \\
\hline I am satisfied with the semi-permanent cosmetic color & 0.807 & 0.258 & 0.230 \\
\hline I am satisfied with the expertise of the practitioner in semi-permanent cosmetics & 0.780 & 0.334 & 0.143 \\
\hline I am satisfied with the natural technique & 0.771 & 0.343 & 0.200 \\
\hline I was relaxed in the treatment environment's atmosphere & 0.218 & 0.891 & 0.112 \\
\hline The appearance of the practitioner is clean and hygiene is maintained & 0.320 & 0.868 & 0.134 \\
\hline The treatment tools and the treatment environment are clean & 0.289 & 0.864 & 0.141 \\
\hline I am satisfied with the procedure time and the first half & 0.184 & 0.135 & 0.878 \\
\hline The pain is fine when I do the procedure & 0.169 & -0.019 & 0.834 \\
\hline $\begin{array}{l}\text { I am satisfied with the full explanation of the semi-permanent makeup procedure } \\
\text { before surgery }\end{array}$ & 0.229 & 0.321 & 0.768 \\
\hline Eigenvalue & 3.001 & 2.729 & 2.265 \\
\hline Distributed description (\%) & 30.015 & 27.270 & 22.648 \\
\hline Cumulative distributed description (\%) & 30.015 & 57.305 & 79.953 \\
\hline Reliability & 0.901 & 0.921 & 0.822 \\
\hline KMO $=0.867 ;$ Bartlett's test $x^{2}=1794.149(\mathrm{df}=45, p=0.000)$ & & & \\
\hline
\end{tabular}

$\mathrm{KMO}$, Kaiser-Meyer-Olkin; df, degree of freedom.

탕으로 요인 명을 부여하였다. 요인 1 (30.015\%)은 '테크닉'으로 명명하였고, 요인 2 (27.270\%)는 '시술환경'으로 명명하였으며, 요인 3 (22.648\%)은 '시술설명'으로 명명하였다. 이 3개의 요인 적재 값이 \pm 0.4 이상으로 나타나 추출된 요인은 타당성이 확보 된 것으로 분석되었으며, 신뢰도 또한 0.60 이상으로 나타나 신 뢰할만한 수준인 것으로 볼 수 있다.

\section{3. 기술통계적 분석}

1) 반영구화장 선호도

반영구화장 선호도를 분석한 결과는 Table 4 와 같다. 분석 결과 전체적으로 볼 때, '테크닉 선호' ( $\mathrm{M}=3.81)$, '트렌드 선호' $(\mathrm{M}=3.14)$ 순으로 나타났으며, 전반적인 반영구화장 선호도는 평균 3.47점으로 나타났다.

일반적 특성에 따라 반영구화장 선호도에 차이가 있는지를 분 석한 결과, 먼저 성별에 따라서는 선호도의 하위요인별 테크닉 선 호 $(p<0.001)$, 트렌드 선호 $(p<0.01)$ 에 대해 통계적으로 유의미한 차이가 나타났으며, 여자의 경우 남자에 비해 상대적으로 테크닉 선호가 높은 것으로 나타난 반면 남자의 경우 여자에 비해 상대적 으로 트렌드 선호가 높은 것으로 나타나 차이를 보였다.

연령에 따라서는 선호도의 하위요인별 테크닉 선호에 대해 통 계적으로 유의미한 차이가 나타났으며 $(p<0.01), 20$ 대에 비해 30 대 이상의 경우 상대적으로 테크닉 선호가 높은 것으로 나타났다.

결혼 여부에 따라서는 선호도의 하위요인별 테크닉 선호에 대 해 통계적으로 유의미한 차이가 나타났으며 $(p<0.01)$, 미혼에 비
해 기혼의 경우 상대적으로 테크닉 선호가 높은 것으로 나타났 다.

최종 학력에 따라서는 전반적인 선호도 $(p<0.01)$ 와 하위요인별 테크닉 선호 $(p<0.001)$ 에 대해 통계적으로 유의미한 차이가 나타 났으며, 4 년제 졸업 이하에 비해 대학원 졸업의 경우 상대적으로 전반적인 선호도와 하위요인별 테크닉 선호가 높은 것으로 나타 났다.

직업에 따라서는 전반적인 선호도와 하위요인별 테크닉 선호 및 트렌드 선호에 대해 통계적으로 유의미한 차이가 나타났으며 $(p<0.001)$, 전문직의 경우 상대적으로 전반적인 선호도와 하위 요인별 테크닉 선호가 높은 것으로 나타났고, 교육직이나 서비스 업의 경우 상대적으로 테크닉 선호가 높은 것으로 나타나 차이를 보였다.

월평균 소득에 따라서는 전반적인 선호도와 하위요인별 테 크닉 선호에 대해 통계적으로 유의미한 차이가 나타났으며 $(p<0.05), 200$ 만원 미만에 비해 200 만원 이상의 경우 상대적으 로 전반적인 선호도와 하위요인별 테크닉 선호가 높은 것으로 나 타났다.

2) 반영구화장 시술만족도

반영구화장 시술만족도를 분석한 결과는 Table 5 와 같다. 분석 결과 전체적으로 볼 때, '시술환경' $(\mathrm{M}=3.45)$ 이 가장 높게 나타났 고, '테크닉' (M=3.37), '시술설명' $(\mathrm{M}=3.13)$ 순으로 나타났으며, 전반적인 반영구화장 시술만족도는 평균 3.32점으로 나타났다. 
Table 4. Difference in semi-permanent makeup preference according to general characteristics

\begin{tabular}{|c|c|c|c|c|c|c|c|}
\hline \multirow{3}{*}{ Item } & & \multicolumn{4}{|c|}{ Semi-permanent makeup preference } & \multirow{2}{*}{\multicolumn{2}{|c|}{ Total }} \\
\hline & & \multicolumn{2}{|c|}{$\begin{array}{l}\text { Technique } \\
\text { preference }\end{array}$} & \multicolumn{2}{|c|}{$\begin{array}{c}\text { Trend } \\
\text { preference }\end{array}$} & & \\
\hline & & M & SD & M & SD & M & SD \\
\hline \multirow{3}{*}{ Gender } & Female & 3.87 & 0.674 & 3.08 & 0.778 & 3.48 & 0.521 \\
\hline & Male & 3.29 & 0.508 & 3.56 & 0.697 & 3.42 & 0.525 \\
\hline & $t$-value $(p)$ & \multicolumn{2}{|c|}{$4.582^{\star * * *}(0.000)$} & \multicolumn{2}{|c|}{$-3.162^{* *}(0.002)$} & \multicolumn{2}{|c|}{$0.556(0.579)$} \\
\hline \multirow{5}{*}{ Ages } & 20-29 years old & $3.53^{a}$ & 0.764 & 3.30 & 0.750 & 3.41 & 0.533 \\
\hline & 30-39 years old & $3.91^{b}$ & 0.597 & 3.19 & 0.807 & 3.55 & 0.540 \\
\hline & 40-49 years old & $3.86^{b}$ & 0.604 & 3.05 & 0.709 & 3.46 & 0.434 \\
\hline & $50-59$ years old & $3.90^{\mathrm{b}}$ & 0.747 & 3.03 & 0.905 & 3.47 & 0.629 \\
\hline & $F$-value $(p)$ & \multicolumn{2}{|c|}{$4.566^{* *}(0.004)$} & \multicolumn{2}{|c|}{$1.569(0.197)$} & \multicolumn{2}{|c|}{$0.753(0.522)$} \\
\hline \multirow{3}{*}{ Marital status } & Single & 3.61 & 0.762 & 3.22 & 0.722 & 3.42 & 0.518 \\
\hline & Married & 3.88 & 0.634 & 3.10 & 0.804 & 3.49 & 0.522 \\
\hline & $t$-value $(p)$ & \multicolumn{2}{|c|}{$-2.750^{* *}(0.007)$} & \multicolumn{2}{|c|}{$1.110(0.268)$} & \multicolumn{2}{|c|}{$-1.092(0.276)$} \\
\hline \multirow{5}{*}{ Final education } & High school graduate or below & $3.68^{a}$ & 0.722 & 3.13 & 0.779 & $3.41^{a}$ & 0.533 \\
\hline & College graduate & $3.85^{a}$ & 0.592 & 3.03 & 0.700 & $3.44^{\mathrm{a}}$ & 0.391 \\
\hline & University graduate & $3.94^{a}$ & 0.560 & 3.20 & 0.809 & $3.57^{\mathrm{a}}$ & 0.508 \\
\hline & Graduate school & $4.56^{b}$ & 0.410 & 3.19 & 0.989 & $3.88^{b}$ & 0.599 \\
\hline & F-value $(p)$ & \multicolumn{2}{|c|}{$8.043^{* * *}(0.000)$} & \multicolumn{2}{|c|}{$0.385(0.784)$} & \multicolumn{2}{|c|}{$4.165^{* *}(0.007)$} \\
\hline \multirow{8}{*}{ Job } & Student & $3.29^{a}$ & 0.643 & $3.30^{\mathrm{bc}}$ & 0.740 & $3.30^{\mathrm{a}}$ & 0.499 \\
\hline & Self-employment & $3.80^{\mathrm{b}}$ & 0.423 & $2.83^{\mathrm{a}}$ & 0.643 & $3.31^{\mathrm{a}}$ & 0.400 \\
\hline & Service business & $4.00^{\mathrm{b}}$ & 0.888 & $3.35^{b c}$ & 0.833 & $3.67^{\mathrm{bc}}$ & 0.651 \\
\hline & Profession & $3.91^{\mathrm{b}}$ & 0.697 & $3.56^{\mathrm{c}}$ & 0.729 & $3.73^{c}$ & 0.528 \\
\hline & Education & $4.07^{b}$ & 0.626 & $3.10^{\mathrm{ab}}$ & 0.820 & $3.58^{\mathrm{bc}}$ & 0.473 \\
\hline & Housewife & $3.84^{\mathrm{b}}$ & 0.604 & $2.93^{\mathrm{ab}}$ & 0.817 & $3.38^{\mathrm{ab}}$ & 0.522 \\
\hline & Others & $3.92^{b}$ & 0.603 & $2.97^{\mathrm{ab}}$ & 0.605 & $3.45^{\mathrm{ab}}$ & 0.426 \\
\hline & $F$-value $(p)$ & \multicolumn{2}{|c|}{$6.738^{* * *}(0.000)$} & \multicolumn{2}{|c|}{$4.348^{* * *}(0.000)$} & \multicolumn{2}{|c|}{$4.221^{* * *}(0.000)$} \\
\hline \multirow{5}{*}{ Monthly average income } & $<1$ million won & $3.65^{\mathrm{a}}$ & 0.689 & 3.14 & 0.761 & $3.39^{\mathrm{a}}$ & 0.453 \\
\hline & 1-2 million won & $3.84^{\mathrm{ab}}$ & 0.629 & 2.98 & 0.808 & $3.41^{\mathrm{a}}$ & 0.574 \\
\hline & 2-3 million won & $3.98^{b}$ & 0.637 & 3.33 & 0.765 & $3.66^{b}$ & 0.530 \\
\hline & $\geq 3$ million won & $3.95^{b}$ & 0.726 & 3.16 & 0.789 & $3.56^{\mathrm{ab}}$ & 0.532 \\
\hline & F-value $(p)$ & \multicolumn{2}{|c|}{$3.661^{*}(0.013)$} & \multicolumn{2}{|c|}{$1.879(0.134)$} & \multicolumn{2}{|c|}{$3.468^{*}(0.017)$} \\
\hline Total & & 3.81 & 0.682 & 3.14 & 0.783 & 3.47 & 0.521 \\
\hline
\end{tabular}

${ }^{*} p<0.05 ;{ }^{* *} p<0.01 ;{ }^{* * *} p<0.001$; Duncan $(\mathrm{a}<\mathrm{b}<\mathrm{c})$, a group with a significant mean difference is denoted by $\mathrm{a}<\mathrm{b}<\mathrm{c}$, with $\mathrm{c}$ being the largest group, and a being the smallest group.

$\mathrm{M}$, mean; SD, standard deviation.

일반적 특성에 따라 반영구화장 시술만족도에 차이가 있는지 를 분석한 결과, 먼저 연령대에 따라서는 전반적인 시술만족도와 하위요인별 테크닉에 대해 통계적으로 유의미한 차이가 나타났 으며 $(p<0.05), 20$ 대나 40 대에 비해 30 대에서 상대적으로 전반 적인 시술만족도와 하위요인별 테크닉에 대한 만족도가 높은 것 으로 나타났다.

결혼여부에 따라서는 시술만족도의 하위요인별 시술환경에 대
해 통계적으로 유의미한 차이가 나타났으며( $p<0.05)$, 기혼의 경 우 미혼에 비해 상대적으로 시술환경에 대한 만족도가 높은 것으 로 나타났다.

최종 학력에 따라서는 시술만족도의 하위요인별 시술설명에 대해 통계적으로 유의미한 차이가 나타났으며 $(p<0.05), 4$ 년제 졸업 이하에 비해 대학원 졸업의 경우 상대적으로 시술설명에 대 한 만족도가 높은 것으로 나타났다. 
Table 5. Difference in satisfaction with semi-permanent makeup procedure according to general characteristics

\begin{tabular}{|c|c|c|c|c|c|c|c|c|c|}
\hline \multirow{3}{*}{ Item } & & \multicolumn{6}{|c|}{ Satisfaction with semi-permanent makeup } & \multirow{2}{*}{\multicolumn{2}{|c|}{ Total }} \\
\hline & & \multicolumn{2}{|c|}{$\begin{array}{l}\text { Procedure } \\
\text { description }\end{array}$} & \multicolumn{2}{|c|}{ Technique } & \multicolumn{2}{|c|}{$\begin{array}{c}\text { Procedure } \\
\text { environment }\end{array}$} & & \\
\hline & & M & SD & M & SD & M & SD & M & SD \\
\hline \multirow{3}{*}{ Gender } & Female & 3.13 & 0.769 & 3.37 & 0.778 & 3.46 & 0.818 & 3.33 & 0.653 \\
\hline & Male & 3.08 & 0.688 & 3.38 & 0.642 & 3.36 & 0.737 & 3.28 & 0.397 \\
\hline & $t$-value $(p)$ & \multicolumn{2}{|c|}{$0.379(0.705)$} & \multicolumn{2}{|c|}{$-0.090(0.928)$} & \multicolumn{2}{|c|}{$0.682(0.496)$} & \multicolumn{2}{|c|}{$0.525(0.602)$} \\
\hline \multirow{5}{*}{ Ages } & $20-29$ years old & 3.10 & 0.766 & $3.20^{\mathrm{a}}$ & 0.674 & 3.27 & 0.818 & 3.19 & 0.530 \\
\hline & $30-39$ years old & 3.27 & 0.743 & $3.68^{b}$ & 0.755 & 3.51 & 0.929 & $3.51^{\mathrm{b}}$ & 0.671 \\
\hline & $40-49$ years old & 3.11 & 0.702 & $3.23^{\mathrm{a}}$ & 0.801 & 3.43 & 0.706 & $3.25^{\mathrm{a}}$ & 0.649 \\
\hline & $50-59$ years old & 3.01 & 0.866 & $3.47^{\mathrm{ab}}$ & 0.681 & 3.63 & 0.794 & $3.38^{\mathrm{ab}}$ & 0.602 \\
\hline & $F$-value $(p)$ & \multicolumn{2}{|c|}{$1.222(0.302)$} & \multicolumn{2}{|c|}{$6.037^{* *}(0.001)$} & \multicolumn{2}{|c|}{$1.928(0.125)$} & \multicolumn{2}{|c|}{$3.221^{*}(0.023)$} \\
\hline \multirow{3}{*}{ Marital status } & Single & 3.22 & 0.778 & 3.28 & 0.638 & 3.29 & 0.828 & 3.27 & 0.497 \\
\hline & Married & 3.09 & 0.751 & 3.41 & 0.805 & 3.51 & 0.794 & 3.34 & 0.673 \\
\hline & $t$-value $(p)$ & \multicolumn{2}{|c|}{$1.280(0.202)$} & \multicolumn{2}{|c|}{$-1.298(0.196)$} & \multicolumn{2}{|c|}{$-2.037^{*}(0.043)$} & \multicolumn{2}{|c|}{$-1.010(0.314)$} \\
\hline \multirow{5}{*}{ Final education } & High school graduate or below & $3.09^{a}$ & 0.820 & 3.37 & 0.771 & 3.37 & 0.868 & 3.29 & 0.659 \\
\hline & College graduate & $3.31^{\mathrm{ab}}$ & 0.632 & 3.25 & 0.664 & 3.36 & 0.548 & 3.30 & 0.436 \\
\hline & University graduate & $3.01^{\mathrm{a}}$ & 0.671 & 3.38 & 0.785 & 3.63 & 0.723 & 3.34 & 0.619 \\
\hline & Graduate school & $3.58^{b}$ & 0.571 & 3.79 & 0.782 & 3.78 & 1.018 & 3.73 & 0.756 \\
\hline & $F$-value $(p)$ & \multicolumn{2}{|c|}{$2.872^{*}(0.037)$} & \multicolumn{2}{|c|}{$1.554(0.201)$} & \multicolumn{2}{|c|}{$2.451(0.064)$} & \multicolumn{2}{|c|}{$1.850(0.139)$} \\
\hline \multirow{8}{*}{ Job } & Student & $2.95^{\mathrm{ab}}$ & 0.652 & $3.15^{\mathrm{a}}$ & 0.636 & 3.20 & 0.746 & $3.10^{\mathrm{a}}$ & 0.392 \\
\hline & Self-employment & $2.81^{\mathrm{a}}$ & 0.915 & $3.49^{a b}$ & 0.680 & 3.64 & 0.559 & $3.33^{\mathrm{abc}}$ & 0.506 \\
\hline & Service business & $3.63^{c}$ & 0.557 & $3.36^{\mathrm{ab}}$ & 1.036 & 3.75 & 0.906 & $3.56^{c}$ & 0.785 \\
\hline & Profession & $3.25^{\mathrm{bc}}$ & 0.907 & $3.49^{a b}$ & 0.818 & 3.57 & 0.769 & $3.44^{\mathrm{bc}}$ & 0.742 \\
\hline & Education & $2.86^{a}$ & 0.608 & $3.17^{\mathrm{a}}$ & 0.834 & 3.30 & 0.705 & $3.12^{\mathrm{a}}$ & 0.589 \\
\hline & Housewife & $3.38^{\mathrm{bc}}$ & 0.713 & $3.63^{b}$ & 0.676 & 3.54 & 0.881 & $3.53^{\mathrm{c}}$ & 0.639 \\
\hline & Others & $2.96^{\mathrm{ab}}$ & 0.660 & $3.21^{\mathrm{a}}$ & 0.652 & 3.36 & 0.900 & $3.18^{\mathrm{ab}}$ & 0.592 \\
\hline & $F$-value $(p)$ & \multicolumn{2}{|c|}{$5.580^{* * *}(0.000)$} & $2.943^{*}$ & $0.009)$ & 2.030 & $.062)$ & $4.005^{*}$ & $0.001)$ \\
\hline & $<1$ million won & $3.09^{a}$ & 0.669 & 3.38 & 0.783 & 3.34 & 0.864 & 3.28 & 0.593 \\
\hline & 1-2 million won & $3.08^{a}$ & 0.925 & 3.35 & 0.694 & 2.55 & 0.767 & 3.33 & 0.671 \\
\hline $\begin{array}{l}\text { Monthly average } \\
\text { income }\end{array}$ & 2-3 million won & $3.42^{b}$ & 0.808 & 3.49 & 0.765 & 3.56 & 0.725 & 3.49 & 0.637 \\
\hline & $\geq 3$ million won & $2.99^{a}$ & 0.560 & 3.27 & 0.815 & 3.45 & 0.808 & 3.24 & 0.626 \\
\hline & $F$-value $(p)$ & $3.028^{*}$ & $.030)$ & 0.672 & .570) & 1.254 & .291) & 1.498 & 216) \\
\hline Total & & 3.13 & 0.759 & 3.37 & 0.763 & 3.45 & 0.809 & 3.32 & 0.629 \\
\hline
\end{tabular}

${ }^{*} p<0.05 ;{ }^{* *} p<0.01 ;{ }^{* * *} p<0.001$; Duncan $(\mathrm{a}<\mathrm{b}<\mathrm{c})$, a group with a significant mean difference is denoted by a $<\mathrm{b}<\mathrm{c}$, with $\mathrm{c}$ being the largest group, and a being the smallest group.

$\mathrm{M}$, mean; SD, standard deviation.

직업에 따라서는 전반적인 시술만족도 $(p<0.01)$ 와 하위요인별 시술설명 $(p<0.001)$, 테크닉 $(p<0.01)$ 에 대해 통계적으로 유의미 한 차이가 나타났으며, 주부는 전반적인 시술만족도와 하위요인 별 테크닉, 시술환경에 대한 만족도가 높았고, 서비스업의 경우 는 전반적인 시술만족도와 하위요인별 시술설명, 시술환경에 대 한 만족도가 높은 것으로 나타났다.

월평균 소득에 따라서는 시술만족도의 하위요인별 시술설명에 대해 통계적으로 유의미한 차이가 나타났으며 $(p<0.05), 200-$
300 만원 미만의 경우는 그 외 모든 소득층보다 상대적으로 시술 설명에 대한 만족도가 높은 것으로 나타났다. 이 외에 성별에 따 라서는 통계적으로 유의미한 차이가 나타나지 않았다( $p>0.05)$.

\section{4. 가설의 검증}

1) 각 변수 간 상관관계 검증

각 변수 간 상관관계를 알아보기 위하여 상관관계 검증을 실시 한 결과는 Table 6 과 같다. 분석결과 반영구화장 선호도의 하위 
요인별 테크닉 선호 $(\mathrm{r}=0.408 ; p<0.001)$, 트렌드 선호 $(\mathrm{r}=0.174$; $p<0.01)$ 는 시술설명 만족도와 통계적으로 유의미한 정(+)의 상 관관계가 있는 것으로 나타났고, 반영구화장 선호도의 하위요 인별 테크닉 선호 $(\mathrm{r}=0.316 ; p<0.001)$, 트렌드 선호 $(\mathrm{r}=0.186$; $p<0.01)$ 는 테크닉 만족도와 통계적으로 유의미한 정 $(+)$ 의 상관 관계가 있는 것으로 나타났다. 또한 반영구화장 선호도의 하위요 인별 테크닉 선호 $(\mathrm{r}=0.365 ; p<0.001)$, 트렌드 선호 $(\mathrm{r}=0.276$; $p<0.001)$ 는 시술환경 만족도와 통계적으로 유의미한 정(+)의 상 관관계가 있는 것으로 나타났다.

\section{2) 가설 1 의 검증}

$\mathrm{H} 1$. 반영구화장 선호도가 시술설명 만족도에 정(+)의 영향을 미칠 것이다.

$\mathrm{H} 1-1$. 테크닉 선호는 시술설명 만족도에 정(+)의 영향을 미 칠 것이다

H1-2. 트렌드 선호는 시술설명 만족도에 정(+)의 영향을 미 칠 것이다.

반영구화장 선호도가 시술설명 만족도에 미치는 영향을 검증 하기 위하여 다중회귀분석을 실시한 결과는 Table 7과 같다. 분 석결과 회귀모형의 설명력은 $19.6 \%$ 이고, 회귀식은 통계적으 로 유의미한 것으로 분석되었다 $(F=31.498 ; p<0.001)$. 독립변 수별로는 테크닉 선호 $(p<0.001)$, 트렌드 선호 $(p<0.01)$ 가 시술 설명 만족도에 통계적으로 유의미한 정 $(+)$ 의 영향을 미치는 것 으로 나타났다. 즉, 테크닉 선호가 높아지면 시술설명 만족도는 0.407의 상승이 있는 것으로 나타났고, 트렌드 선호가 높아지면 시술설명 만족도는 0.172 의 상승이 있는 것으로 나타났다. 따라 서 반영구화장 시술 경험자의 시술설명 만족도에 있어서는 테크 닉 선호, 트렌드 선호가 중요한 요인임을 알 수 있다. 시술만족 도를 향상시키기 위해서는 시술 전 고객과의 충분한 상담을 통해 사전 디자인 작업이 선행되어야 하며, 이때 고객이 선호하는 디 자인에 전문가의 견해가 상호 절충되어 디자인이 결정되는 것이
시술 및 고객만족도에 긍정적인 영향을 미친다고 하였다(Hong, 2017; Park, 2016). 또한 Kim \& Park (2016)의 연구에서도 전문가의 시술 전 충분한 설명이 만족도가 높아진다고 하였다. 이는 뷰티 분야가 트렌드에 민감하기 때문에 최신 트렌드가 적용 되고 고객이 원하는 테크닉이 시술된다면 고객이 체감하는 시술 만족도가 향상될 것으로 판단되어 본 연구결과를 뒷받침 해준다.

\section{3) 가설 2 의 검증}

$\mathrm{H} 2$. 반영구화장 선호도가 테크닉 만족도에 정(+)의 영향을 미 칠 것이다.

$\mathrm{H} 2-1$. 테크닉 선호는 테크닉 만족도에 정(+)의 영향을 미칠 것이다.

$\mathrm{H} 2-2$. 트렌드 선호는 테크닉 만족도에 정(+)의 영향을 미칠 것이다.

반영구화장 선호도가 테크닉 만족도에 미치는 영향을 검증하 기 위하여 다중회귀분석을 실시한 결과는 Table 8과 같다. 분석 결과 회귀모형의 설명력은 $13.4 \%$ 이고, 회귀식은 통계적으로 유 의미한 것으로 분석되었다 $(F=20.056 ; p<0.001)$. 독립변수별로 는 테크닉 선호 $(p<0.001)$, 트렌드 선호 $(p<0.01)$ 가 테크닉 만족 도에 통계적으로 유의미한 정(+)의 영향을 미치는 것으로 나타 났다. 즉, 테크닉 선호가 높아지면 테크닉 만족도는 0.315의 상 승이 있는 것으로 나타났고, 트렌드 선호가 높아지면 테크닉 만 족도는 0.184 의 상승이 있는 것으로 나타났다. 따라서 반영구화 장 시술 경험자의 테크닉 만족도에 있어서는 테크닉 선호, 트렌 드 선호가 중요한 요인임을 알 수 있다. Park (2016)와 Seo \& Lee (2013)는 좋은 테크닉이 시술의 재작업, 클레임, 고객 불만 족의 원인 등으로 인한 비용을 감소시킬 뿐만 아니라 치열한 경 쟁업소와 차별화시키는 전략이라고 하여 본 연구결과를 뒷받침 해준다.

\section{Table 6. Correlation between variables}

\begin{tabular}{|c|c|c|c|c|c|c|}
\hline \multirow[b]{2}{*}{ Item } & & \multicolumn{2}{|c|}{ Preference } & \multicolumn{3}{|c|}{ Procedure satisfaction } \\
\hline & & $\begin{array}{l}\text { Technique } \\
\text { preference }\end{array}$ & Trend preference & $\begin{array}{l}\text { Procedure } \\
\text { description }\end{array}$ & Technique & $\begin{array}{c}\text { Procedure } \\
\text { environment }\end{array}$ \\
\hline \multirow{2}{*}{ Preference } & $\begin{array}{l}\text { Technique } \\
\text { preference }\end{array}$ & 1 & & & & \\
\hline & Trend preference & 0.005 & 1 & & & \\
\hline \multirow{3}{*}{$\begin{array}{l}\text { Procedure } \\
\text { satisfaction }\end{array}$} & $\begin{array}{l}\text { Procedure } \\
\text { description }\end{array}$ & $0.408^{* * *}$ & $0.174^{* *}$ & 1 & & \\
\hline & Technique & $0.316^{* * *}$ & $0.186^{* *}$ & $0.472^{* * *}$ & 1 & \\
\hline & $\begin{array}{l}\text { Procedure } \\
\text { environment }\end{array}$ & $0.365^{* * *}$ & $0.276^{* * *}$ & $0.353^{* * *}$ & $0.590^{* * *}$ & 1 \\
\hline
\end{tabular}

${ }^{* *} p<0.01 ;{ }^{* * *} p<0.001$. 
Table 7. Effects of semi-permanent makeup preference on satisfaction with procedure description

\begin{tabular}{|c|c|c|c|c|c|}
\hline \multirow[t]{2}{*}{ Item } & \multicolumn{2}{|c|}{$\begin{array}{l}\text { Non-standardization } \\
\text { factor }\end{array}$} & \multirow{2}{*}{$\begin{array}{c}\text { Standardization factor } \\
\beta\end{array}$} & \multirow[t]{2}{*}{$t$} & \multirow[t]{2}{*}{$p$} \\
\hline & B & SE & & & \\
\hline Constant & 0.882 & 0.293 & & 3.012 & 0.003 \\
\hline Technique preference & 0.452 & 0.062 & 0.407 & $7.298^{* * *}$ & 0.000 \\
\hline Trend preference & 0.167 & 0.054 & 0.172 & $3.082^{* *}$ & 0.002 \\
\hline \multicolumn{6}{|c|}{$\mathrm{R}^{2}=0.196 ;$ Adj. $\mathrm{R}^{2}=0.189 ; F=31.498^{* * *} ; p=0.000$} \\
\hline
\end{tabular}

${ }^{* *} p<0.01 ;{ }^{* * *} p<0.001 ; \mathrm{SE}$, standard error; B, unstandardized coefficient; $\beta$, standardized coefficient; $t, t$-value; $\mathrm{R}^{2}$, correlation coefficient; $F$, F-value; Adj., adjust.

Table 8. Effects of semi-permanent makeup preference on technique satisfaction

\begin{tabular}{|c|c|c|c|c|c|}
\hline \multirow[t]{2}{*}{ Item } & \multicolumn{2}{|c|}{$\begin{array}{l}\text { Non-standardization } \\
\text { factor }\end{array}$} & \multirow{2}{*}{$\begin{array}{c}\text { Standardization factor } \\
\beta\end{array}$} & \multirow[t]{2}{*}{$t$} & \multirow[t]{2}{*}{$p$} \\
\hline & B & SE & & & \\
\hline Constant & 1.467 & 0.305 & & 4.805 & 0.000 \\
\hline Technique preference & 0.353 & 0.065 & 0.315 & $5.456^{* * *}$ & 0.000 \\
\hline Trend preference & 0.180 & 0.056 & 0.184 & $3.188^{* *}$ & 0.002 \\
\hline
\end{tabular}

${ }^{* *} p<0.01 ;{ }^{* * *} p<0.001 ; \mathrm{SE}$, standard error; B, unstandardized coefficient; $\beta$, standardized coefficient; $t, t$-value; $\mathrm{R}^{2}$, correlation coefficient; $F$, F-value; Adj., adjust.

Table 9. Effects of semi-permanent makeup preference on satisfaction with procedure environment

\begin{tabular}{|c|c|c|c|c|c|}
\hline \multirow[t]{2}{*}{ Item } & \multicolumn{2}{|c|}{$\begin{array}{l}\text { Non-standardization } \\
\text { factor }\end{array}$} & \multirow{2}{*}{$\begin{array}{c}\text { Standardization factor } \\
\beta\end{array}$} & \multirow[t]{2}{*}{$t$} & \multirow[t]{2}{*}{$p$} \\
\hline & B & SE & & & \\
\hline Constant & 0.920 & 0.309 & & 2.973 & 0.003 \\
\hline Technique preference & 0.431 & 0.065 & 0.364 & $6.582^{* * *}$ & 0.000 \\
\hline Trend preference & 0.284 & 0.057 & 0.275 & $4.967^{* * *}$ & 0.000 \\
\hline
\end{tabular}

${ }^{* *} p<0.01 ;{ }^{* * *} p<0.001 ; \mathrm{SE}$, standard error; B, unstandardized coefficient; $\beta$, standardized coefficient; $t, t$-value; $\mathrm{R}^{2}$, correlation coefficient; $F$, F-value; Adj., adjust.

\section{4) 가설 3 의 검증}

H3. 반영구화장 선호도가 시술환경 만족도에 정(+)의 영향을 미 칠 것이다.

H3-1. 테크닉 선호는 시술환경 만족도에 정(+)의 영향을 미칠 것 이다.

H3-2. 트렌드 선호는 시술환경 만족도에 정(+)의 영향을 미칠 것 이다.

반영구화장 선호도가 시술환경 만족도에 미치는 영향을 검증하기 위하여 다중회귀분석을 실시한 결과는 Table 9 와 같다. 분석결과 회 귀모형의 설명력은 $20.9 \%$ 이고, 회귀식은 통계적으로 유의미한 것으 로 분석되었다 $(F=34.171 ; p<0.001)$. 독립변수별로는 테크닉 선호, 트렌드 선호가 시술환경 만족도에 통계적으로 유의미한 정(+)의 영
향을 미치는 것으로 나타났다( $p<0.001)$. 즉, 테크닉 선호가 높아지 면 시술환경 만족도는 0.364 의 상승이 있는 것으로 나타났고, 트렌 드 선호가 높아지면 시술환경 만족도는 0.275 의 상승이 있는 것으로 나타났다. 따라서 반영구화장 시술 경험자의 시술환경 만족도에 있 어서는 테크닉 선호, 트렌드 선호가 중요한 요인임을 알 수 있다. 반 영구화장의 감염과 예방은 시술환경과 관련이 깊은데 시술장소의 바 닥위생관리와 폐기물 처리의 실천도가 낮으면 고객의 클레임으로 연 결되고, 시술장소는 뷰티숍보다는 의료기관에서 시술 시 만족도가 높았다(Seo \& Kang, 2015). 또한 시술환경은 시술자가 작업할 수 있는 쾌적하고 효율적인 공간과 편의성, 디자인 방법과 자세에 따라 테크닉이 달라질 수 있고, 트렌드를 적용한 최신 기법과 장기 등은 시술환경과 밀접한 관련이 있기에 본 연구결과를 뒷받침 해준다. 


\section{Conclusion}

본 연구는 최근 뷰티분야에 실용 테크닉으로 부각되고 있는 반 영구화장 선호도가 시술만족도에 미치는 영향에 대해서 검증하 였으며, 연구결과는 다음과 같다.

첫째, 반영구화장 선호도가 시술설명 만족도에 미치는 영향에 대해서 알아본 결과, 독립변수별로 테크닉 선호와 트렌드 선호가 높아지면 시술설명 만족도가 높아진다. 이는 뷰티분야가 시각적 으로 보이는 부분이 크고 트렌드에 민감한 산업이기 때문이라고 판단된다.

둘째, 반영구화장 선호도가 테크닉 만족도에 미치는 영향에 대 해서 알아본 결과, 독립변수별로 테크닉 선호와 트렌드 선호가 높아지면 테크닉 만족도가 높아진다. 이는 반영구화장도 메이크 업의 한 부분이기에 트렌드와 직접적인 관련이 있고, 눈썹형태 및 피부타입에 따른 적합하고 새롭고 다양한 기법이 적용된다면 테크닉에 대한 만족도가 향상될 것으로 유추한다.

셋째, 반영구화장 선호도가 시술환경 만족도에 미치는 영향에 대해서 알아본 결과, 독립변수별로 테크닉 선호와 트렌드 선호가 높아지면 시술환경 만족도가 높아진다. 이는 반영구화장의 시술 환경은 작업자의 작업 편의성, 작업자세 등에 따라 테크닉이 달 라질 수 있고, 최신 트렌드의 기기를 활용한 반영구기법이 적용 된다면 전반적인 시술환경의 만족도가 높아질 것이라고 판단된 다.

따라서 반영구화장은 미적 감각과 뷰티 트렌드에 민감한 분 야이기에, 시술설명, 테크닉, 시술환경에 대한 다양하고 효율적 인 방법이 개선 및 향상된다면 반영구화장에 대한 고객의 만족도 는 더욱더 높아질 것이다. 또한 이를 통해 반영구산업은 물론이 고 뷰티와 관련된 염료 및 화장품, 기기산업까지 동반 성장하여 실용메이크업의 한 분야에 활용도 높게 자리매김 할 것을 기대한 다.

본 연구를 진행함에 있어 연구대상자의 연령을 20-50대로 한 정하였고, 시술경험자를 토대로 조사하다 보니 주로 여성의 분포 가 높았다. 하지만 차후 진행되는 연구에서는 반영구화장에 대한 인식조사를 여성과 남성의 동일비율로 조사하는 것, 또한 연구 대상자의 연령을 좀 더 폭넓게 산정하여 다양한 의견을 연구하는 것이 의미가 있다고 판단되어 이를 후속 연구로 제안한다.

\section{References}

Anderson EW, Fornell C, Lehmann DR. Customer satisfaction, market share, and profitability: findings from Sweden. Journal of Marketing, 58: 53-66, 1994.

Baek KO, Park DH. Cognition of modern people for tattoo and utilities of tattoo according to the social and cultural properties. Journal of the Korean Society of Cosmetology, 23: 73-90, 2017.

Bloemer J, Ruyter K. On the relationship between store image, store satisfaction and store loyalty. European Journal of Marketing, 32: 499-513, 1998.

Choi SE. Facial image perception and appearance management behavior based on female university students' satisfaction with their faces. Asian Journal of Beauty and Cosmetology, 15: 85-95, 2017.

Cho $\mathrm{MH}$, Yang JH. Image perception according to face shapes and makeup color variation. Asian Journal of Beauty and Cosmetology, 15: 122-131, 2017.

Cho SY, Lee JM. A study on semi-permanent special makeup technique for effective eyebrow correction. Journal of the Korean Society of Cosmetology, 19: 822-832, 2013.

Chung EH, Ko BJ, Kwon SB, Kim HJ, Jung GH, Lee SH, Lee SY, Cho MK. Comparison of the degree of semipermanent makeup removal and histological changes using 1064 nm Q-switched ND: YAG laser. Journal of Dermatological Science, 84: e88, 2016.

Deter-Wolf A, Robitaille B, Krutak L, Galliot S. The world's oldest tattoos. Journal of Archaeological Science: Reports, 5: 19-24, 2016.

Hill P, Culp J. Permanent makeup: tips and techniques. Thomson Delmar Learning, New York, p180, 2006.

Hong SN. The effect of semi-permanent makeup treatment satisfaction on positivity or negativity effect. Journal of the Korean Society of Cosmetology, 23: 187-197, 2017.

Kim DY, Choi TB. A research in experienced customer's perception levels on semi-permanent makeup: comparison of Korea, Japan and America. Journal of the Korean Society of Cosmetology, 20: 1083-1090, 2014.

Kim S, Park DH. Comparison of awareness and purchase satisfaction for semi-permanent make-up between Korean and Chinese women. Journal of the Korean Society of Cosmetology, 22: 781-791, 2016.

Park GH. A study of the effects of semi-permanent makeup, customers' psychological satisfaction, and customers' intention to get the treatment again and recommend it to others. Journal of the Korean Society of Beauty and Art, 17: 189-205, 2016.

Seo EK, Kang SW. Awareness and practice on the prevention of bloodborne infection among semipermanent makeup 
workers. Journal of the Korean Society of Beauty and Art, 16: 147-157, 2015.

Seo RS, Lee JM. A study on the desired cosmetics benefits and semi permanent make-up preference by pursuit image: focusing on women in their 20s 50s. Journal of the Korean Society of Cosmetology, 19: 621-633, 2013.

Seo RS. A study on male's semi-permanent preferences by pursued image: focused in the 20s-50s motives of appearance management, preference in semipermanent and re-treatment intentions. Journal of the Korean Society of Cosmetology, 19: 545-556, 2013.

Shelton JA, Peters CL. Actions speak as loud as products: disposition as a self-perceptive method of identity incorporation. Consumption Markets \& Culture, 9: 207233, 2006. 


\section{국문초록}

\section{반영구화장 선호도가 시술만족도에 미치는 영향}

홍수남

부천대학교 뷰티융합비즈니스과, 경기도 부천시, 한국

목적: 최근 뷰티분야에 실용테크닉으로 부각되고 있는 반영구화장 선호도가 시술만족도에 미치는 영향에 대해서 검증하고자 본 연 구를 수행하였다. 방법: 서울, 경기에 거주하는 20-50대 여성을 연구대상으로 설문하여 총 262 부를 통계분석에 활용하였고, 자료 수집기간은 2017년 2월 20일부터 2017년 4월 5일까지이다. 자료분석 방법은 빈도분석, 신뢰도분석, 독립표본 $t$-test 및 one-way analysis of variance (ANOVA) 분석을 실시하였으며, 사후분석으로는 Duncan test를 실시하였고, 상관관계분석과 선형회귀분석을 실시하였다. 결과: 첫째, 반영구화장 선호도가 시술설명 만족도에 미치는 영향에 대해서 알아본 결과, 통계적으로 유의미한 영향을 미치는 것으로 나타났다. 즉, 독립변수별로 테크닉 선호와 트렌드 선호가 높아지면 시술설명 만족도가 높아진다. 둘째, 반영구화장 선호도가 테크닉 만족도에 미치는 영향에 대해서 알아본 결과, 통계적으로 유의미한 영향을 미치는 것으로 나타났다. 즉, 독립변수 별로 테크닉 선호와 트렌드 선호가 높아지면 테크닉 만족도가 높아진다. 셋째, 반영구화장 선호도가 시술환경 만족도에 미치는 영 향에 대해서 알아본 결과, 통계적으로 유의미한 영향을 미치는 것으로 나타났다. 즉, 독립변수별로 테크닉 선호와 트렌드 선호가 높 아지면 시술환경 만족도가 높아진다. 결론: 반영구화장은 미적 감각과 뷰티트렌드에 민감한 분야이기에, 시술설명, 테크닉, 시술환 경에 대한 방법이 개선 및 향상된다면 반영구화장에 대한 고객만족도는 더욱더 높아질 것이다.

핵심어: 반영구화장, 영구메이크업, 메이크업, 선호도, 만족도

\section{참고문헌}

김도연, 최태부. 반영구화장에 대한 경험 고객의 인식도 조사: 한국, 일본, 미국 비교. 한국미용학회지, 20: 1083-1090, 2014.

김승아, 박두현. 한국과 중국여성의 반영구 화장의 인식과 구매 만족도의 비교. 한국미용학회지, 22: 781-791, 2016. 박건희. 반영구 화장의 시술 및 심리적 만족도가 재시술 및 추천의도에 미치는 영향. 한국인체미용예술학회지, $7: 189-$ 205, 2016.

백경옥, 박두현. 현대인의 사회 및 문화적 속성에 따른 타투와 타투의 유용성에 관한 인식. 한국미용학회지, 23: 73-90, 2017.

서란숙, 이정민. 추구이미지에 따른 화장추구혜택 및 세미퍼머넌트 메이크업 선호도에 관한 연구: 20-50대 여성을 중심으

로. 한국미용학회지, 19: 621-633, 2013.

서란숙. 추구이미지에 따른 남성중심의 세미퍼머넌트 연구: 20-50대 남성의 외모관리동기 및 세미퍼머넌트 메이크업 선 호도, 재시술의도를 중심으로. 한국미용학회지, 19: 545-556, 2013.

서은경, 강성욱. 혈행성 감염관리에 대한 인식과 실천에 관한 연구: 반영구화장종사자를 중심으로. 한국인체미용예술학회

지, 16: $147-157,2015$.

조민희, 양진희. 얼굴형과 메이크업 색상변화에 따른 이미지 지각에 관한 연구. 아시안뷰티화장품학술지, 15: 122-131, 2017.

조소영, 이정민. 효과적인 눈썹보정을 위한 반영구 특수메이크업 기법 연구. 한국미용학회지, 19: 822-832, 2013.

최승은. 여대생의 얼굴 만족여부에 따른 얼굴이미지 인식과 외모관리행동에 관한 연구. 아시안뷰티화장품학술지, $15:$

85-95, 2017.

홍수남. 반영구화장의 시술만족도가 긍정성 및 부정성 효과에 미치는 영향. 한국미용학회지, 23: 187-197, 2017. 


\section{中文摘要}

\section{半永久性化妆的偏好度对美容术满意度的影响}

洪洙男

富川大学美容融和商业学科，京畿道富川市，韩国

目的: 这项研究旨在验证半永久性化妆术的偏好效果，这是美容行业近期的一项实用技术，探讨其对美容术满 意度的影响。方法: 这项研究的对象是分别居住在首尔和京畿道的20到50岁的女性，共262份问卷进行分析。 资料收集期为 2017 年2月20日至2017年4月5日。数据分析方法包括频率分析，可靠性分析，独立样本 $t$ 检验和 单因素方差分析（one-way analysis of variance, ANOVA）。Duncan测试用于后期分析 ; 相关和线性回归 分析也被利用分析。结果: 第一, 发现牛永久性化妆偏好度对美容术描述满意度的影响具有统计显着性, 即每 个自变量的技术和趋势偏好越高, 对美容术描述的满意程度越高。第二, 这种偏好对技术满意度的影响也被发 现具有统计显着性, 即每个自变量的技术和趋势偏好越高, 技术满意度越高。最后, 这种半永久性化妆偏好度 对美容术环境满意度的影响也被发现具有统计意义, 即每个自变量的技术和趋势偏好越高, 美容术环境的满意 度越高。结论: 由于半永久性化妆是一种对美感和美容趋势敏感的领域。若美容术的说明, 技术和环境得到改 善，顾客对半永久化妆术的满意度将会增加。

关键词: 牛永久性化妆, 永久化妆, 化妆, 偏好度, 满意度 
